g/day when their patients were on Nutrizym (mean fat excretion $42.5 \mathrm{~g}$ ) compared with when they were on Pancrex $\mathrm{V}$ forte (mean fat excretion $57.3 \mathrm{~g}$ ). Our patients' fat excretion was closely similar with both products $(25.3 \mathrm{~g}$ on Nutrizym and $24.3 \mathrm{~g}$ on Pancrex V forte). Before the start of our trial patients had been taking Pancrex $\mathrm{V}$ forte in a dosage which had been established by the parents as being the most effective one for reducing stool frequency and improving stool character. All patients continued with this regimen for the first two weeks of the trial so that dosage and relevant details could be recorded, and the number of tablets was halved (though the enzyme dose for trypsin and lipase remained the same) during the two weeks when Nutrizym was given. Knill-Jones et al. (1970) chose to use suboptimal doses of pancreatic replacement therapy to facilitate the detection of improved digestion with either of the two preparations. Our doses resulted in smaller faecal fat excretions, but these were still sufficiently abnormal, we believe, for any differences in the effectiveness of the tablets to be apparent.

In addition we did not find a significant difference in stool volume (mean volume $294 \mathrm{ml} /$ day on Nutrizym and $259 \mathrm{ml} /$ day on Pancrex V forte). Knill-Jones et al. (1970), who recorded stool weights (444 g/day on Nutrizym and $514 \mathrm{~g}$ /day on Pancrex $\mathrm{V}$ forte), pointed out that the reduction in stool weight was not significant.

A consideration of the dosage regimen chosen by Knill-Jones et $a l$. in their trial may explain the differences between their findings and ours. The analysis of the enzyme content of the tablets used in their trial (trypsin and lipase 2,500 and 8,100 units respectively for Nutrizym, and 1,230 and 4,000 units respectively for Pancrex $\mathrm{V}$ forte) suggests that a dosage ratio of two tablets of Pancrex $\mathrm{V}$ forte to one tablet of Nutrizym would have been approximately equivalent. The ratio of three tablets of Pancrex V forte to two tablets of Nutrizym used by Knill-Jones et al., however, represented a reduction in Pancrex $\mathrm{V}$ forte dosage of $25 \%$. The relative increase of the Nutrizym dose may have been sufficient to account for the reported decreases in stool fat and stool weight.

Our method of evaluating protein digestion by a measurement of urine urea excretion did not show an enhancement of nitrogen absorption with either product. Protein digestion as assessed by Knill-Jones et al. by the measurement of urine hydroxyproline excretion after a gelatin meal was not practicable for use in our children on an outpatient basis. Thus we are unable to comment on their observation that "the proteolytic action of Nutrizym started earlier and finished before that of Pancrex," though we note the observation that "the total effect over eight hours is similar."
Though the laboratory investigations did not provide any evidence in favour of either product the final questionnaire completed by the parents showed some patient preference for Nutrizym. There was some discrepancy (unexplained) between the information on stool frequency and character and the occurrence of abdominal pain obtained during the course of the trial, when there was no patient preference, and the information obtained at the end, when some of the parents modified their views in favour of Nutrizym. Clearly it is more convenient, especially for those patients who take a high dose of pancreatic preparation, to be able to reduce the number of tablets.

With the exception of the two children whose coefficients of fat absorption were nil (table III) values obtained for the children while on pancreatic replacement therapy were comparable with those in previous reports (Harris et al., 1955; Ross, 1955; Matthew and Spector, 1961), and the mean value $(70 \%)$ was some $28 \%$ less than normal $(96 \% \pm 4 \%$ ) (Matthews and Spector, 1961).

The apparent absence of fat absorption in cases 2 and 5 is difficult to explain. Both children were taking high doses of pancreatic therapy (mean numbers of Pancrex $\mathrm{V}$ forte and Nutrizym tablets per week were 133 and 63 respectively for case 2 , and 378 and 214 respectively for case 5 ). One patient (case 2 ), aged 6.6 years, was on the 75th centile for weight, and the other (case 5), aged 8.7 years, was on the 10 th centile.

Pancreatic enzyme preparations, even in high dosage, do not eliminate the steatorrhoea of cystic fibrosis and it seems expedient to investigate other mechanisms which may influence fat absorption in this disease.

We thank E. Merck Ltd. for financial help and Mr. M. Fletcher for technical work. M.C.G. is in receipt of a grant from the Cystic Fibrosis Research Trust.

\section{References}

Anderson, C. M., et al. (1952). Lancet, 1, 836.

Bosnes, R. W., and Taussky, H. H. (1945). Fournal of Biological Chemistry, 158,581 .

Coltini, E. P., Gallina, D. L., and Dominguez, J. M. (1973). Fournal of Nutrition, 103, 11

Fawcett, J. K., and Scott, J. E. (1960). Fournal of Clinical Pathology, 13, 156. Harris, R., Norman, A. P., and Payne, W. W. (1955). Archives of Disease in Childhood, 30, 424

Knill-Jones, R. P., et al. (1970). British Medical fournal, 4, 21.

Lapey, A., et al. (1974). Fournal of Pediatrics, 84, 328.

Matthews, L. W., and Spector, S. (1961). Pediatrics, 27, 351.

Ross, C. A. C. (1955). Archives of Disease in Childhood, 30, 316.

Van de Kamer, J. H., Huinink, H. ten Bokkel, and Weijers, H. A. (1949). fournal of Biological Chemistry, 177, 347.

\title{
Pain Threshold Analysis in Patients with Osteoarthrosis of Hip*
}

\author{
SUSAN L. O'DRISCOLL, MALCOLM I. V. JAYSON
}

British Medical fournal, 1974, 3, 714-715

\section{Summary}

The pain threshold was measured in patients with osteoarthrosis of the hip. The pain threshold was significantly

*From a paper read at the Heberden Society Meeting, Bristol, June, 1974.

Department of Medicine, University of Bristol, Bristol BS2 8HW, and Royal National Hospital for Rheumatic Diseases, Bath

SUSAN L. O'DRISCOLL, M.B., M.R.C.P., Senior Registrar in Rheumatology MALCOLM I. V. JAYSON, M.D., M.R.C.P., Consultant Senior Lecturer in Rheumatology lower in patients who required surgery than in controls. After successful surgery the threshold rose to normal levels. In patients with few or no symptoms from their osteoarthritic hips the pain threshold was high. Insensitivity to pain does not predispose towards osteoarthrosis of the hip. Indeed, the severity of symptoms can be directly related to an increased sensitivity to pain in osteoarthritic subjects.

\section{Introduction}

Pain is generally regarded as a protective sensation. If the threshold for a noxious stimulus to just produce the symptom 
of pain is high then a subject may be more liable to damage joints and develop degenerative joint disease. This is thought to be one of the mechanisms by which Charcot joints develop in patients with congenital or acquired insensitivity to pain. Alternatively, if the pain threshold plays no part in the development of arthritis then it may be related to the severity of the symptoms. A low pain threshold implies that the subject feels pain more easily and therefore may suffer more severe symptoms. With a high threshold pain is less readily appreciated so that the arthritis is less of a problem.

The present study was directed at determining the pain threshold in patients with osteoarthrosis of the hip.

\section{Methods}

Measurements of pain threshold were obtained in the following groups of patients: (1) Twenty-one patients (six men, 15 women), with a mean age of 67.3 years, with primary osteoarthrosis of the hip who were awaiting total hip replacement. Only patients whose radiographic changes in the joints were of grades III or IV measured by reference to the Atlas of Standard Radiographs of Arthritis (Council for International Organizations of Medical Sciences, 1963) were included; (2) Twenty-two patients (nine men, 13 women) with primary osteoarthrosis of the hip after successful total hip replacement. Their average age was 69.2 years. In nine of these patients sequential measurements were made before and after surgery; (3) twelve patients (five men, seven women) with grade III or IV primary osteoarthrosis of the hip but with insufficient symptoms to merit surgery. Their average age was 70.4 years; (4) a control group of 21 subjects (three men, 18 women) with an average age of 70.5 years matched to the preoperative group.

The pain threshold was quantified by Keele's method (1954) using a slightly modified algometer. This consisted of a small plunger applied to the centre of the forehead. The pressure was steadily increased using a calibrated spring. The rate of pressure increase was $1 \mathrm{~kg} / \mathrm{sec}$, the time being measured with a metronome. When the patient spontaneously complained of pain that pressure was taken as the pain threshold. Repeated measurements were taken until three consecutive readings were within $0.5 \mathrm{~kg}$ of each other. The test was performed in a standardized fashion. Preliminary studies by ourselves, by Keele (1954), and by Huskisson and Hart (1972) have shown that pain threshold measurements obtained by this method are reproducible.

\section{Results}

The pain threshold in the preoperative group was significantly lower than that in the controls $(P<0.05$; fig. 1$)$. There was no difference between the controls and the postoperative group $(P>0 \cdot 10)$, but the pain threshold was considerably higher in

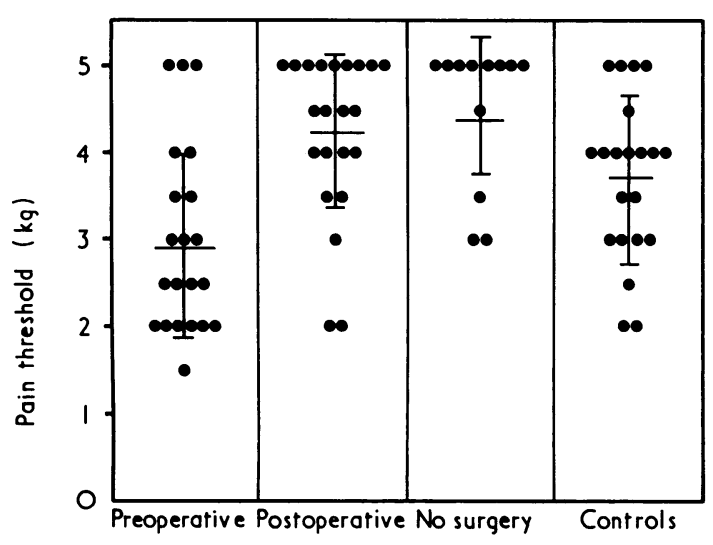

FIG. 1-Pain thresholds in four groups showing means \pm i S.D.

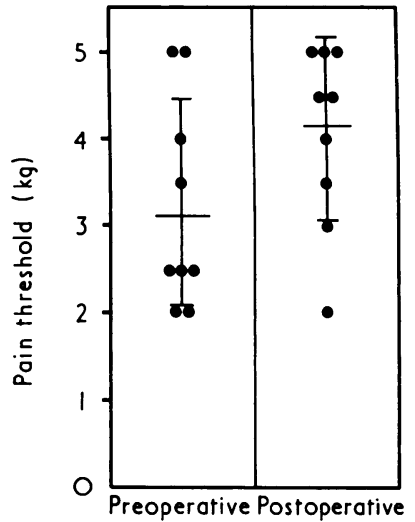

FIG. 2-Pain thresholds in nine patients studied before and after surgery, showing means \pm 1 S.D.

the postoperative group than in the preoperative patients $(P<0.001)$. An increase in the threshold was observed in the nine patients who were studied before and after surgery $(P<0.01$; fig. 2). Despite comparable radiographic changes the pain threshold was higher in the 12 patients who did not need surgery than in the preoperative group $(P<0.001)$, and it was also slightly higher than in the controls $(P<0.05)$.

\section{Discussion}

The interpretation of pain is difficult. One definition is "any sensation which the brain interprets as unpleasant." A key word is "sensation" but more important is "interprets." Pain is a subjective phenomenon. Without awareness of it in the brain pain does not exist, only neurological impulses.

There are three components of pain. Firstly, there is the sensory component which indicates the location, quality, and duration of the sensation; secondly, the cognitive componentthe interpretation of the sensation as harmful or unpleasantand, thirdly, the affective component, which is concerned with the level of attention which the sensation is given.

There are many different forms of noxious stimulus which can be used to quantify the pain threshold and, obviously, the results vary according to the degrees of involvement of each of these three factors. Beecher (1959) described different techniques used in order to measure the pain threshold. The technique using the pressure algometer is simple and reproducible (Keele, 1954; Merskey and Spear, 1964), and its value has been shown in cardiac pain (Keele, 1968) and in rheumatoid arthritis and ankylosing spondylitis (Huskisson and Hart, 1972). Though formal psychological testing was not undertaken there did not appear to be any undue anxiety in any of the subjects tested, nor have we noted any change in the pain threshold associated with anxiety.

The results do not support the thesis that a high pain threshold predisposes towards damage and osteoarthrosis of the hip. They suggest that exposure to chronic pain lowers the pain threshold and so increases the symptoms. With decrease of stimulation of peripheral receptors after successful surgery the pain threshold can return to normal. If the pain threshold does not fall in osteoarthrosis of the hip then the symptoms are not so severe, and surgery is less likely to be indicated.

\section{References}

Beecher, H. I. (1959). Measurement of Subjective Responses. New York Oxford University Press.

Council for International Organizations of Medical Sciences (1963). Atlas of Standard Radiographs of Arthritis, Vol. 1 and 2 . Oxford,Blackwell. Huskisson, E. C., and Hart, D. F. (1972). British Medical Fournal, 4, 193. Keele, K. D. (1954). Lancet, 1, 636 .

Keele, K. D. (1968). British Medical fournal, 1, 670

Merskey, H., and Spear, F. G. (1964). British fournal of Social and Clinical Psychology, 3, 130. 